\title{
Correlates of HIV infection among transgender women in two Chinese cities
}

\author{
Duo Shan ${ }^{1}$, Mao-He Yu², Jie Yang ${ }^{3}$, Ming-Hua Zhuang ${ }^{4}$, Zhen Ning ${ }^{4}$, Hui Liu' ${ }^{1}$ Lu Liu', Meng-Jie Han ${ }^{1}$ and \\ Da-Peng Zhang ${ }^{1 *}$
}

\begin{abstract}
Background: In an era when HIV transmission has been on the rise among men who have sex with men (MSM), transgender women may play a considerable role in China's current HIV epidemic as a potential "bridge" of HIV transmission between homosexual and heterosexual populations. We sought to understand the risk behaviours and factors associated with HIV infection among transgender women in two cities in China.
\end{abstract}

Methods: From January to December 2016, we recruited transgender women with the help of community-based organizations (CBOs) through a wide range of methods, including snowball sampling. After recruitment, we asked participants to fill out a structured questionnaire including questions about socio-demographics, sexual behaviours, condom use, substance use and uptake of health care services. HIV infection status was determined by using two different rapid testing reagents.

Results: Among 498 subjects enrolled in this study, 233 were from Shanghai and 265 were from Tianjin. The median age was 30 years (range: 18-68; IQR: 24-33). Of them, 337 (67.7\%) preferred feminine dress, 13 (2.6\%) had undergone transsexual operation and 68 (13.7\%) had used hormones for transition purposes. Nearly half (45.6\%) reported having regular partners, and 351 (70.5\%) had casual partners. Regarding condom use, $81.5 \%$ reported not always using condoms with stable partners, and $70.9 \%$ reported not using condoms with casual partners. Twentyfive (5.0\%) had a history of buying sex and fifty-one (10.2\%) had a history of selling sex in the past three months. A total of 200 (40.2\%) participants had used at least one kind of controlled substance in the past six months. The most commonly used substances were amyl nitrates (rush popper) (99.5\%) and 5-MeO-DiPT (20.0\%). Among rush popper users, 170 (85.4\%) reported always having sex while on the drug, and 177 (88.9\%) reported increased sexual pleasure after using the drug. The HIV infection risk factors identified in our study were being located in Shanghai $(\mathrm{aOR}=9.35,95 \% \mathrm{Cl}=3.89-22.49)$, selling sex in the past three months $(\mathrm{aO} R=3.44,95 \% \mathrm{Cl}=1.31-9.01)$, and substance use in the past six months $(a O R=5.71,95 \% C l=2.63-12.41)$.

Conclusions: Transgender women bear a high HIV burden in the two Chinese cities. Those involved in commercial sex tended to have inconsistent condom use, leading to high risk of HIV infection. Substance use was an independent risk factor of HIV infection by increasing sexual activities and unprotected sex, which indicated an aggravated and complex situation with possible interacting syndemic factors that could cumulatively facilitate sexual risk behaviours and HIV infection in transgender women. There is an urgent need for innovative and appropriate HIV prevention programmes targeting this unique population. Efforts should be made to provide them with tailored services including persuasive communication on consistent condom use, substance use counselling and related referral services, all with the goal of reducing HIV epidemic among transgender women.

Keywords: HIV, AIDS, Men who have sex with men, Transgender women, Substance use, Risk behaviour

\footnotetext{
*Correspondence: zhangdapeng@chinaaids.cn

'National Center for AIDS/STD Control and Prevention, Chinese Center for

Disease Control and Prevention, Beijing 102206, People's Republic of China

Full list of author information is available at the end of the article
}

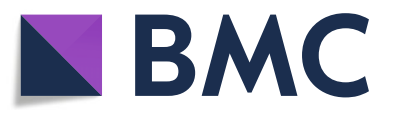

(c) The Author(s). 2018 Open Access This article is distributed under the terms of the Creative Commons Attribution 4.0 International License (http://creativecommons.org/licenses/by/4.0/), which permits unrestricted use, distribution, and reproduction in any medium, provided you give appropriate credit to the original author(s) and the source, provide a link to the Creative Commons license, and indicate if changes were made. The Creative Commons Public Domain Dedication waiver (http://creativecommons.org/publicdomain/zero/1.0/) applies to the data made available in this article, unless otherwise stated. 


\section{Multilingual abstracts}

Please see Additional file 1 for translations of the abstract into the five official working languages of the United Nations.

\section{Background}

The transgender population is a hidden sexual minority, composed of a diverse group of individuals who feel their gender is something other than the one they were assigned at birth [1]. In this article, we use the term "transgender women" to denote those designated male at birth who identify themselves as women among men who have sex with men (MSM) whether or not they have engaged in gender transition or enhancement procedures. Available data show that self-identifying transgender women represent over $10 \%$ of the total MSM population [2]. For a long time transgender women, a sub-group with different behavioural characteristics, have been included with MSM on behavioural and disease surveillance studies but have not received targeted intervention. Since 2007, when sexual transmission overtook injection drug use in China as the dominant mode of HIV transmission (38.9\% for sexual transmission vs $29.2 \%$ for injection drug use), the proportion of homosexual transmission has shown a consistent upwards trend. Of the annual new cases diagnosed between 2007 and 2016, the proportion of homosexual transmission increased markedly from $3.4 \%$ in 2007 to $27.6 \%$ in 2016 [3-5]. Given the rapidly and continually escalating HIV epidemic among MSM, the Chinese government issued the State Council's Five-Year Plan of Action for HIV Prevention (2016-2020) in 2017. This plan emphasized more effective and targeted interventions among MSM, and clearly specified that HIV high risk behaviours among this population should be reduced more than $10 \%$ by 2020 [6].

To achieve this goal, it is necessary to analyse the HIV epidemic among MSM in-depth. In fact, the risk behaviours of transgender women, a group that is often misclassified as the general MSM, have been neglected over the years. In international research studies, HIV prevention among transgender women has attracted much attention and the extent of the studies varies in different regions. Previous studies indicated that transgender women have a higher risk of HIV infection compared with the general MSM population, in part due to gender identity issues, social and economic levels, commercial sex and other risky behaviours, and family and social discrimination [7]. A systematic review of transwomen sex workers revealed a 4-fold higher risk for HIV compared to non-transwomen sex workers [8]. Meanwhile, high rates of drug use in this population have also been reported. The reported proportion of transgender women using drugs range from 12 to $34 \%$ [9]. Data from studies of transgender populations in the United States revealed syndemic dynamics that facilitated high-risk sexual behaviours and HIV transmission [10]. Available studies demonstrated an HIV prevalence of $27.7 \%$ among this population in the US, $21.6 \%$ in Pakistan, approximately $11-13 \%$ in Thailand, 25-34\% in Jakarta and 32.2\% in Peru [11-14].

Yet data on the prevalence of HIV among transgender women in China are still lacking, and the few published studies among Chinese transgender women only focused on cross-dressers involving in sex work with relatively small sample sizes, which is understandable since it would be relatively easy to identify them from appearance and recruit them into studies; also, these programmes only sought to understand the sexual behaviours and characteristics of these individuals without any further information on HIV rates [15-17]. Based on existing limited surveys, this specific group of transgender women has been characterized as male but often dressed as female, most of them were involved in commercial sex with preference of servicing heterosexual men, and also MSM. Anal sex services were mostly provided in entertainment clubs, urban fringe, parks and other hidden areas. More importantly, in recent days, many experts have indicated that this population may play a considerable role in China's current HIV infection as a potential "bridge" of HIV transmission between homosexual and heterosexual populations.

In an era when HIV transmission has been on the rise among MSM, and given the necessity and importance of more targeted interventions among this population, efforts to better understand the transgender women population are needed in order to develop better interventions. Unfortunately, to our knowledge studies that could reliably represent the population of transgender women in China have yet to be conducted or reported in peer-reviewed literature, largely because this is a hard-to-reach and often hidden population. Current understanding about transgender women may not reflect the true situation. Meanwhile, there is still no research evidence documenting HIV rates among Chinese transgender women. This data is essential to inform future HIV intervention strategies. In this study, supported by the M.A.C. AIDS Fund, we collaborated with Chinese community-based organizations (CBOs) to recruit MSM with a focus on transgender women. We anticipate that our study will inform how best to focus future HIV prevention efforts among transgender women in China.

\section{Methods \\ Study site}

This cross-sectional study was conducted in two cities (Shanghai and Tianjin) in China from January to December, 2016. Study cities were selected mainly based on the capacity of local CBOs in reaching transgender women. Several criteria were considered when selecting the city: (1) local Centre for Disease Control and Prevention 
(CDC) had a close working relationship with local CBOs; (2) local CBOs had demonstrated capacity and rich work experience with HIV prevention programmes for MSM; (3) local $\mathrm{CBOs}$ had some preliminary field work experience with transgender women, and were willing to actively cooperate with China CDC to investigate this population.

The basic situation of local CBOs in both cities and their roles in HIV prevention are described as follows:

\section{Shanghai commercial sex workers (CSW) \& MSM center}

The organization was established and registered as a non-government organization in 2004. It mainly conducts outreach, testing and training andmaintains regular communications with sex workers and MSM every week, keeping track of their problems and needs and providing relevant consultation and health services, especially one-to-one, privacy-protected and professional counselling and HIV rapid testing. It also provides a variety of rights and health trainings for sex workers and MSM on a regular basis.

\section{Tianjin Shenlan public health consultation service center}

It is a non-profit social organization established in 2004 and was registered with local civil affairs in 2014. It focuses on Lesbians, Gays, Bisexuals, Transgender (LGBT) community culture development, policy advocacy, youth health education, HIV counselling and rapid testing, CBOs capacity building, and technical support. Both organizations have established good relationship with the transgender community, which is critically important for recruitment process of our research.

\section{Recruitment methods}

All participants enrolled in the study met the three minimum inclusion criteria: (1) aged 18 and above; (2) had anal or oral sexual behaviour with a male partner in the past six months; and (3) were willing to provide informed consent and take HIV tests. Local CBOs played a key role in this process by offering HIV interventions and testing mobilization through peer education, outreach services, and web-based interventions.

Specifically, we recruited transgender women in cooperation with $\mathrm{CBO}$ s through a wide range of methods. First, snowball sampling method was used to recruit the study subjects through the following process: $\mathrm{CBO}$ staff contacted key informants of the transgender women community and asked them to mobilize their peers to join our study. In order to encourage the participants to recommend and mobilize their peers to participate in our programme, we made simplified information, education and communication (IEC) brochures on HIV prevention and appointment cards, and then disseminated to them to facilitate interpretation of the programme for their peers. The mobilized peers, after completing the on-site investigation process, continued to mobilize their peers, and the cycle was thus repeated. Throughout the course of this study, we emphasized the importance of appointment mechanism based on the actual situation on each study site and the number of appointments depended on the workload of the sites. Second, outreach methods were used to recruit cross-dressers who performed as actresses in gay entertainment venues and to recruit transgender women sex workers in venues where they tended to gather, such as urban fringe and construction sites. In addition, social media were extensively applied by sending messages on HIV testing in network groups, chatting with visitors of MSM chat rooms and specifically with potential transgender women on applications including QQ (Version 8.9, Tencent, Shenzhen, China), WeChat (Version 6.7.3, Tencent, Shenzhen, China), and Blued (Version 6.6.3, Blue city, Beijing, China).

To minimize possible selection bias, once a potential participant was approached, he will be asked if his psychological gender is different from his physical gender. If the self-identified sexual identity was uncertain, they would be determined by their preference in feminine dress and by asking their experience of breast augment surgery, reproductive system reconstruction and other gender-related surgery, and hormone use, etc. If they met one of the above classifiable criteria, they would be included as transgender women. Participants who did not meet selection criteria were referred to local Voluntary Counselling and Testing (VCT) clinics.

Throughout the process, CBOs were responsible for advocacy, recruitment and on-site investigations, and CDCs were responsible for on-site quality control. Before the investigation, the $\mathrm{CBOs}$ were given strict and focused training on survey content, methods, and skills. After the investigation, local CDCs conducted the on-site check of the questionnaires, and corrected them in a timely manner once problems were found. In addition, staff from China CDC randomly selected and re-examined the questionnaires to check the data for consistency and accuracy.

\section{Data collection}

Recruited participants were informed of the nature and purpose of the study and survey procedures, and asked to sign an informed consent form. Participants were also told of the risks and benefits of the programme (including referrals for other services needed), and their ability to cease participation at any time without penalty. Each participant was asked to fill out a structured questionnaire which consisted of two parts. The first part collected information on socio-demographic background, sexual behaviours, condom use, substance use, as well as STI history. This part was completed either by the participant or by the CBOs'staff while they interviewed the 
participant, which took between 30 and $40 \mathrm{~min}$ to complete. The second part included the results of HIV and syphilis screening and confirmatory testing. Each questionnaire was given a unique identification number. For quality control purpose, standardized training was carried out for all CBO staff who were responsible for recruiting and interviewing the participants. All participants were provided with HIV post-test counselling and HIV-positive participants were referred to their local CDCs for free counselling and evaluation for treatment.

\section{HIV testing services HIV testing}

In our study, CBOs provided HIV rapid tests for MSM with technical support from the local CDCs. The rapid tests were conducted using two kinds of reagents: finger prick test kits (the Determine HIV-1/2 ${ }^{\circ}$ Rapid Test, Abbott Laboratories, Chicago, USA) and oral test kits (the Aware Determine HIV- $1 / 2^{\circ}$ Rapid Test, Calypte Biomedical Corporation, Pleasanton, USA). If the result of rapid tests were negative, it was deemed as negative; and if one of the results was reactive, it was then checked by another kind of rapid test kit; when both of the results were positive, it was deemed as HIV positive.

\section{Data analysis}

Data was double entered and crosschecked with EpiData 3.1 (EpiData Association, Odense, Denmark) to establish the database and statistical analysis was performed using SPSS 19.0 (SPSS Inc., Illinois, USA). Frequency distribution and percentages were calculated for categorical variables; median and interquartile range (IQR) were calculated for continuous variables with non-normal distribution. Pearson's chi-square test was used to compare the socio-demographic characteristics including age group, marital status, residency, education, occupation, and average monthly income in two study sites. In addition, feminine dress preference, gender-related surgery, and hormone use were also compared to see the distribution consistency of this population across the two study sites. The chi-square test was employed in the univariable analysis to examine the factors associated with HIV infection by computing crude odds ratios (cORs) with 95\% confidence intervals (CIs). We further analysed independent risk factors of HIV infection among transgender women using Multivariable logistic regression analysis through stepwise elimination to adjust for confounders, and adjusted ORs (aORs) with 95\% CIs were calculated. Variables were chosen to enter into the multivariate model based on the result of univariable analysis, and together with those from a priori hypothesis from literature. These included study sites, age group, local residency, education, buying sex in the past three months, selling sex in the past three months, substance use in the past six months, and ever had discrimination-related experience in hospitals. Missing values were treated as separate categories for clarity, but otherwise were not treated differently. All testing was two-sided with statistical significance defined at the level of 0.05 .

\section{Results}

\section{Socio-demographic characteristics}

Among the 498 participants enrolled in this study, 233 (46.8\%) were from Shanghai and 265 (53.2\%) were from Tianjin. The median age was 30 years (range: 18-68 years; IQR: 24-33). Most of the subjects $(395,79.3 \%)$ were single, with over 13 years' education $(284,57.0 \%)$, and held a full-time job $(305,61.2 \%)$. There were $62.4 \%$ of participants who reported a monthly income between 3001 and 8000 Yuan (equivalent to USD 477-1270). Most of them (67.7\%) preferred feminine dress, and the proportion of gender-related surgery and hormones use were 2.6 and $13.7 \%$, respectively. Of note, $112(22.5 \%)$ desired to have breast augmentation surgery and 160 (32.1\%) desired to have gender reassignment surgery. Significant differences were observed between participants from two cities in "marital status $\left(\chi^{2}=13.53, P<0.05\right)$ ", "local residency" $\left(\chi^{2}=45.7, P<0.05\right)$ and "average monthly income" $\left(\chi^{2}=36.4, \quad P<0.05\right)$. A relatively higher proportion of "cohabited" was seen in Shanghai; while there was a higher proportion of "local residents" and "participants with an average monthly income $\leq \mathrm{RMB}$ 3000 " in Tianjin than that in Shanghai. Detailed data are presented in Table 1.

\section{HIV-related sexual risk behaviours among transgender women}

The median age of sexual debut among the participants was 20 years (range: 12-40 years; IQR: 17-22). Among 498 transgender women, $32(6.4 \%)$ had participated in group sex in the past 3 months, while 227 (45.6\%) had stable partners and $351(70.5 \%)$ had casual partners in the past three months. Regarding condom use, $81.5 \%$ reported not always using condoms with stable partners, and $70.9 \%$ reported not using condoms with casual partners. Twenty-five (5.0\%) had a history of buying sex in the past three months and 20 of them did not insist on using condoms. Fifty-one (10.2\%) had a history of selling sex in the past three months and 43 of them did not insist on using condoms. Over a half $(51.0 \%)$ had an average price for selling sex between RMB 101-500. In addition, $43(84.3 \%)$ sold sex with heterosexual men by dressing as female. See Table 2.

\section{Substance use among transgender women}

A total of $200(40.2 \%)$ of the transgender women had used at least one kind of psychotropic substance, out of 
Table 1 Socio-demographic characteristics $(n=498)$

\begin{tabular}{|c|c|c|c|c|c|}
\hline Variables & Shanghai $(n, \%)$ & Tianjin $(n, \%)$ & Total $(n, \%)$ & $x^{2}$ & $P$ \\
\hline \multicolumn{6}{|l|}{ Age group } \\
\hline$\leq 30$ & $141(60.5)$ & $184(69.4)$ & $325(65.3)$ & \multirow[t]{3}{*}{4.36} & \multirow[t]{3}{*}{0.11} \\
\hline $31-40$ & 64 (27.5) & 57 (21.5) & $121(24.3)$ & & \\
\hline$\geq 41$ & $28(12.0)$ & $24(9.1)$ & $52(10.4)$ & & \\
\hline \multicolumn{6}{|l|}{ Marital status } \\
\hline Single & 177 (76.0) & 218 (82.3) & 395 (79.3) & \multirow[t]{4}{*}{13.53} & \multirow[t]{4}{*}{$<0.05$} \\
\hline Married & 27 (11.6) & $29(10.9)$ & $56(11.2)$ & & \\
\hline Cohabited & $16(6.9)$ & $2(0.8)$ & $18(3.6)$ & & \\
\hline Divorced & $13(5.6)$ & $16(6.0)$ & $29(5.8)$ & & \\
\hline \multicolumn{6}{|l|}{ Local residency } \\
\hline Yes & $104(44.6)$ & $197(74.3)$ & $301(60.4)$ & \multirow[t]{2}{*}{45.76} & \multirow[t]{2}{*}{$<0.05$} \\
\hline No & $129(55.4)$ & $68(25.7)$ & 197 (39.6) & & \\
\hline \multicolumn{6}{|l|}{ Education } \\
\hline$\leq 9$ years & 39 (16.7) & $30(11.3)$ & 69 (13.9) & \multirow[t]{3}{*}{4.28} & \multirow[t]{3}{*}{0.12} \\
\hline 10-12 years & $71(30.5)$ & $74(27.9)$ & $145(29.1)$ & & \\
\hline$>13$ years & $123(52.8)$ & $161(60.8)$ & $284(57.0)$ & & \\
\hline \multicolumn{6}{|l|}{ Occupation } \\
\hline Unemployed & 34 (14.6) & $26(9.8)$ & $60(12.0)$ & \multirow[t]{4}{*}{4.05} & \multirow[t]{4}{*}{0.26} \\
\hline Students & $14(6.0)$ & $18(6.8)$ & $32(6.4)$ & & \\
\hline Full-time job & $144(61.8)$ & $161(60.8)$ & $305(61.2)$ & & \\
\hline Part-time job & 41 (17.6) & 60 (22.6) & $101(20.3)$ & & \\
\hline \multicolumn{6}{|c|}{ Average monthly income (RMB) } \\
\hline$\leq 3000$ & $45(19.3)$ & $86(32.5)$ & $131(26.3)$ & \multirow[t]{3}{*}{36.41} & \multirow[t]{3}{*}{$<0.05$} \\
\hline $3001-8000$ & $142(60.9)$ & $169(63.8)$ & $311(62.4)$ & & \\
\hline$>8000$ & $46(19.7)$ & $10(3.8)$ & $56(11.2)$ & & \\
\hline \multicolumn{6}{|l|}{ Feminine dress } \\
\hline Yes & $152(65.2)$ & $185(69.8)$ & $337(67.7)$ & \multirow[t]{2}{*}{1.19} & \multirow[t]{2}{*}{0.28} \\
\hline No & $81(34.8)$ & $80(30.2)$ & $161(32.3)$ & & \\
\hline \multicolumn{6}{|c|}{ Gender-related surgery (not including breast augmentation surgery) } \\
\hline Yes & $6(2.6)$ & $7(2.6)$ & $13(2.6)$ & \multirow[t]{2}{*}{0.001} & \multirow[t]{2}{*}{0.97} \\
\hline No & $226(97.4)$ & $258(97.4)$ & 484 (97.4) & & \\
\hline \multicolumn{6}{|l|}{ Hormone use } \\
\hline Yes & 36 (15.5) & $32(12.1)$ & 68 (13.7) & \multirow[t]{2}{*}{1.2} & \multirow[t]{2}{*}{0.27} \\
\hline No & $197(84.5)$ & $233(87.9)$ & $430(86.3)$ & & \\
\hline
\end{tabular}

whom 199 used amyl nitrates, or rush poppers, in the past six months. The most commonly used substances were rush popper $(99.5 \%)$ and 5 -MeO-DiPT $(20.0 \%)$. Among the popper users, 170 (85.4\%) reported always having sex while on the drug and none reported no sexual behaviour when using it. The proportions of experiencing increased sexual pleasure and sexual desire after using the drug were 88.9 and $84.9 \%$, respectively. And there were $68.3 \%$ of popper users reported to have an extended sexual duration after using them. Ninety-two $(46.2 \%)$ reported always using condoms on poppers while
$72(36.2 \%)$ reported reduced condom use after using poppers. See Table 3.

HIV prevalence and risk factors associated with HIV infection among transgender women

The prevalence of HIV among transgender women in our study was 7.6\% (38/498), with 3.4\% (9/265) in Tianjin and $12.4 \%(29 / 233)$ in Shanghai. Seven factors had statistically significant associations with HIV infection among transgender women in univariable analysis, and these included being located in Shanghai, not local residents, with an 
Table 2 Risky sexual behaviors among study participants $(n=498)$

\begin{tabular}{lll}
\hline Variables & No. of participants & $\%$ \\
\hline Group sex in the past 3 months & & \\
Yes & 32 & 6.4 \\
No & 466 & 93.6
\end{tabular}

Had stable partner(s) in the past 3 months

$\begin{array}{lll}\text { Yes } & 227 & 45.6 \\ \text { No } & 271 & 54.4\end{array}$

Frequency of condom use in anal sex with stable partner in the past 3 months

$\begin{array}{lll}\text { Never } & 140 & 61.7 \\ \text { Occasionally } & 19 & 8.4 \\ \text { Often } & 26 & 11.4 \\ \text { Always } & 42 & 18.5\end{array}$

Had casual partner(s) in the past 3 months

$\begin{array}{lll}\text { Yes } & 351 & 70.5 \\ \text { No } & 147 & 29.5\end{array}$

Frequency of condom use with casual partners in the past 3 months ${ }^{2}$

$\begin{array}{lll}\text { Never } & 4 & 1.2 \\ \text { Occasionally } & 68 & 20.8 \\ \text { Often } & 160 & 48.9 \\ \text { Always } & 95 & 29.1\end{array}$

Buying sex in the past 3 months

$\begin{array}{lll}\text { Yes } & 25 & 5.0 \\ \text { No } & 473 & 95.0\end{array}$

Frequency of condom use when buying sex in the past 3 months ${ }^{a}$

$\begin{array}{lll}\text { Never or Occasionally } & 3 & 12.5 \\ \text { Often } & 17 & 70.8 \\ \text { Always } & 4 & 16.7\end{array}$

Selling sex in the past 3 months

$\begin{array}{lll}\text { Yes } & 51 & 10.2 \\ \text { No } & 447 & 89.8\end{array}$

Average price for selling sex ${ }^{a}$

$\begin{array}{lll}\leq 100 & 19 & 38.8 \\ 101-500 & 25 & 51.0 \\ >500 & 5 & 10.2\end{array}$

Frequency of condom use when selling sex in the past 3 months $^{a}$

$\begin{array}{ll}\text { Occasionally } & 7 \\ \text { Often } & 36 \\ \text { Always } & 7\end{array}$

$36-72.0$

Selling sex to heterosexual men by dressing as female

\begin{tabular}{ccc} 
Yes & 43 & 84.3 \\
No & 8 & 15.7 \\
\hline
\end{tabular}

Table 3 Substance use among study participants $(n=498)$

\begin{tabular}{lcc}
\hline Variables & No. of participants & $\%$ \\
\hline $\begin{array}{l}\text { Ever used at least one kind of psychotropic substances in the past } 6 \\
\text { months } \\
\text { Yes }\end{array}$ & 200 & 40.2 \\
No & 298 & 59.8 \\
Types of the substances & 199 & \\
Rush popper & 40 & 99.5 \\
5-MeO-DiPT & 13 & 20.0 \\
Methamphetamine + Cocaine & 10 & 6.5 \\
Others & & 5.0
\end{tabular}

Frequency of using rush poppers in the past 6 months

$\begin{array}{lll}<1 \text { time per month } & 55 & 27.6 \\ 1-3 \text { times per month } & 95 & 47.7 \\ \geq 1 \text { time per week } & 49 & 24.6\end{array}$

Sexual behavior whenever using rush popper

$\begin{array}{lll}\text { Occasionally } & 7 & 3.5 \\ \text { Usually } & 22 & 11.1 \\ \text { Always } & 170 & 85.4\end{array}$

Self-reported sexual pleasure after using rush popper

$\begin{array}{lll}\text { Increased } & 177 & 88.9 \\ \text { Reduced } & 4 & 2.0 \\ \text { No Change } & 7 & 3.5 \\ \text { Uncertain } & 11 & 5.5\end{array}$

Self-reported sexual desire after using rush popper

$\begin{array}{lll}\text { Increased } & 169 & 84.9 \\ \text { Reduced } & 4 & 2.0 \\ \text { No Change } & 17 & 8.5 \\ \text { Uncertain } & 9 & 4.5\end{array}$

Compared with not using rush popper, self-reported sexual duration when using it

$\begin{array}{lll}\text { Extended } & 136 & 68.3 \\ \text { Shortened } & 9 & 4.5 \\ \text { No Change } & 34 & 17.1 \\ \text { Uncertain } & 20 & 10.1\end{array}$

Compared with not using rush popper, self-reported condom use when using it

$\begin{array}{lll}\text { Never used } & 3 & 1.5 \\ \text { Sometimes used with increased times } & 1 & 0.5 \\ \text { Sometimes used with reduced times } & 72 & 36.2 \\ \text { Sometimes used with same times } & 31 & 15.6 \\ \text { Always used } & 92 & 46.2\end{array}$

The most frequent circumstances of using rush popper

$\begin{array}{lll}\text { Providing sexual services } & 4 & 2.0\end{array}$

$\begin{array}{lll}\text { For fun } & 182 & 91.5\end{array}$

$13 \quad 6.5$


education level no more than 9 years, buying sex in the past three months, selling sex in the past three months, substance use in the past six months, and ever had discrimination-related experience in hospitals $(P \leq 0.05$, see Table 4). In the multivariable analysis, the HIV infection risk factors identified were being located in Shanghai $(\mathrm{aOR}=9.35,95 \% \mathrm{CI}: 3.89-22.49)$, selling sex in the past three months $(\mathrm{aOR}=3.44,95 \% C I$ : $1.31-9.01)$, and substance use in the past six months $(\mathrm{aOR}=5.71,95 \% \mathrm{CI}$ : 2.63-12.41). It should be noted that "Buying sex in the past three months" had relatively obvious significance in the univariable analysis but had decreased significance with $P=0.05$ in the multivariable analysis. See Table 4 .

\section{Discussion}

Our study showed that HIV prevalence among transgender women in Shanghai and Tianjin were 12.4 and $3.4 \%$, respectively; which were higher than that of general MSM in Shanghai (10.25\%) and Tianjin $(3.0 \%)$ [18, 19].
According to Zhou's study, the pooled prevalence of HIV infection in general MSM in China was 6.5\% [20]. In both study cities, the results were consistent with the fact that compared to the general MSM population, transgender women are at higher risk for HIV considering their risk behaviours. Studies from the US and Southeast Asia also showed disproportionately high rates of HIV among transgender persons, compared to the general MSM population $[11,21]$. In our multivariable analysis, selling sex in the past three months remained significantly associated with HIV infection, as did substance use in the past six months, which were all independent factors related to HIV risk in the other studies [22, 23].

Our study demonstrated different socio-demographic characteristics among transgender women in China. Only $13.7 \%$ took hormones and even fewer (2.6\%) sought the use of surgical procedures. This was not the case among transgender women in US and Thailand, where a majority of transgender people had taken hormones to enhance

Table 4 Univariable and multivariable analysis for risk factors associated with HIV infection among transgender women in two Chinese cities, $2016(n=498)$

\begin{tabular}{|c|c|c|c|c|c|c|}
\hline Variables & No. of participants & HIV infection rate (\%) & $\operatorname{cOR}(95 \% \mathrm{Cl})$ & $P$ & $\mathrm{aOR}(95 \% \mathrm{Cl})$ & $P$ \\
\hline \multicolumn{7}{|l|}{ Study sites } \\
\hline Tianjin & 265 & 3.4 & 1.00 & & 1.00 & \\
\hline Shanghai & 233 & 12.4 & $3.46(1.49-8.01)$ & $<0.01$ & $9.35(3.89-22.49)$ & $<0.01$ \\
\hline \multicolumn{7}{|l|}{ Age group } \\
\hline$\leq 30$ & 325 & 7.1 & 1.00 & & & \\
\hline $31-40$ & 121 & 11.6 & $3.88(0.51-29.40)$ & 0.19 & & \\
\hline$\geq 41$ & 52 & 1.9 & $6.67(0.85-52.15)$ & 0.07 & & \\
\hline \multicolumn{7}{|l|}{ Local residency } \\
\hline Yes & 301 & 5.3 & 1.00 & & & \\
\hline No & 197 & 11.2 & $2.24(1.15-4.38)$ & 0.02 & & \\
\hline \multicolumn{7}{|l|}{ Education } \\
\hline$>13$ years & 284 & 6.0 & 1.00 & & & \\
\hline $10-12$ years & 145 & 6.9 & $1.16(0.52-2.61)$ & 0.71 & & \\
\hline$\leq 9$ years & 69 & 15.9 & $2.98(1.33-6.69)$ & 0.01 & & \\
\hline \multicolumn{7}{|c|}{ Buying sex in the past 3 months } \\
\hline No & 473 & 7.0 & 1.00 & & 1.00 & \\
\hline Yes & 25 & 20 & $3.33(1.18-9.45)$ & 0.02 & $3.59(1.00-12.87)$ & 0.05 \\
\hline \multicolumn{7}{|c|}{ Selling sex in the past 3 months } \\
\hline No & 447 & 6.7 & 1.00 & & 1.00 & \\
\hline Yes & 51 & 15.7 & $2.59(1.12-5.99)$ & 0.03 & $3.44(1.31-9.01)$ & 0.01 \\
\hline \multicolumn{7}{|c|}{ Substance use in the past 6 months } \\
\hline Yes & 298 & 5.0 & 1.00 & & 1.00 & \\
\hline No & 200 & 11.5 & $2.45(1.25-4.82)$ & 0.01 & $5.71(2.63-12.41)$ & $<0.01$ \\
\hline \multicolumn{7}{|c|}{ Ever had discrimination-related experience in hospitals } \\
\hline No & 239 & 3.8 & 1.00 & & & \\
\hline Yes & 259 & 11.2 & $3.22(1.49-6.96)$ & $<0.01$ & & \\
\hline
\end{tabular}


their gender presentation and many had engaged in surgical procedures as well $[24,25]$. Although risky sexual behaviours were not defined consistently across the various studies, we found an alarmingly vast majority of transgender women who could not consistently use condoms with their stable or causal partners. Roughly $10 \%$ of transgender women engaged in commercial sex work in other studies $[1,26]$, in contrast to our finding of $10.2 \%$ selling sex and $5.0 \%$ buying sex. In our study, selling sex was significantly associated with an elevated risk for HIV infection, which was in accordance with other studies [27, 28]. In recent years, more and more news media in China have reported that "prostitution women" arrested by local public security departments turned out to be "male". In fact, we found that due to the cross-dressing characteristic of this population, their recipients of sexual service usually did not know their biological gender as "male" and thought that they were "female". As such, this population could have sexual behaviours both with heterosexual men and MSM, which made them become a population with a higher risk for HIV transmission compared to the general MSM. Based on our initial understanding of this population from the field study, they could be referred to as a group of people "whose number was not large but with extremely high risks of HIV infection and transmission". Indeed, some studies even suggested a high awareness of HIV-related sexual risk behaviours among transgender women but a low priority of HIV prevention compared to other immediate concerns $[10,26]$. Given that this was a "bridge" population of HIV transmission between homosexuality and heterosexuality and in view of the complexity of this population, future HIV routine outreach work among MSM conducted by health staff needs to pay more attention on this subset minority and focus on encouraging their negotiation of consistent condom use with all of their clients whenever involving in commercial sex.

Another unique risk behaviour of HIV among transgender women was the high rate of substance use (40.2\%) in our study, which was much higher than that in two other studies among the general MSM in China [29, 30]; and even higher than transgender women population with reported rates of $30-40 \%$ in other countries [31, 32]. Our study showed that most popper users had self-reported increased sexual activity and increased unprotected sex, which suggested close interrelations between substance use, high-risk sexual behaviours and risk of HIV transmission among this population [33]. Substance use was an independent predictor of HIV infection among transgender women in our study, which indicated an aggravated and complex situation with possible interacting syndemic factors that could cumulatively facilitate sexual risk behaviours and HIV infection in this population. Studies also suggested that substance use before or during sex compromises cognitive or behavioural abilities to use condoms, and synthetic drug use tends to increase the risk of HIV transmission by reducing safe behaviour, increasing the likelihood of random sexual behaviour, and expanding the network of sexual partners [34, 35]. Future HIV prevention programmes needs to focus more on this high-risk subset of transgender women.

There was no significant association found between discrimination-related experience and HIV infection, however, over half reported having had discrimination-related experience in hospitals, which may prevent their access to available HIV services. Although there was inadequate data in our study to verify the direct relations between discrimination and HIV infection, other studies indicated that discrimination among transgender women may contribute to the worsening of their gender transition due to limited HIV prevention and low social support, and in this way, leading to the vulnerability of HIV-related risk behaviours [36, 37].

Our study has several strengths. We systematically described the socio-demographic and risk behaviour characteristics of the self-identifying transgender women, and explored the associated risk factors of HIV infection, which could provide an opportunity for understanding the epidemiology of behaviours and HIV risks among this population. In addition, since studies on Chinese transgender women population have been scarce, especially when there hadn't been well-defined transgender population in China, in our study, CBOs were fully mobilized to utilize multiple channels to find Chinese transgender women population with a clear definition for the first time, which filled the gap in China where this marginalized population was not well understood. The CBOs' involvement in our study strongly guaranteed the sample size of this hard-to-reach population.

The study limitations include a lack of HIV incidence data, qualitative data and an insufficient number of HIV positive samples that prevented a better understanding of risk factors among transgender women. Study participants were selected in ways that did not limit selection biases, and our results could not be nationally representative of this subgroup of MSM. Besides, considering that our subjects were of relatively hidden populations, their emotions and self-efficacy were less represented in our data compared to the behavioural information collected, limiting the richness of the analysis. However, our study does provide correlates of HIV infection that could help facilitate future HIV prevention strategies.

Despite the limitations, our study results have shown that transgender women population actually exists in various forms and statuses in China. We found that this population is not monolithic, but rather nuanced with different risk behaviours, such as involving in commercial 
sex and substance use. This provides a direction for future programmes targeting this high-risk and under-served population, ensuring more focused intervention.

\section{Conclusions}

Our study suggests the urgent need for HIV prevention strategies that are relevant and appropriate in this population. Our findings revealed relatively heightened HIV risks including commercial sex and substance use among Chinese transgender women, which is unique to this population; and a higher HIV prevalence was seen in transgender women than that of the general MSM. In China, despite the high priority for HIV prevention among transgender women, this population has neither become a part of national HIV surveillance system nor received specific HIV prevention. Actually, transgender women were often included with the general MSM in HIV programmes in China [38, 39], but without targeted HIV prevention strategy for this independent subgroup of MSM. Since over a half of the transgender women in our study ever had discrimination-related experience in hospitals, which may prevent their access to comparable health services, improved health service provided by hospitals built on current HIV testing may be an important approach. As this is a relatively hidden population, the approach needs to go beyond traditional prevention methods by training the key informants and influential social network leaders of transgender women communities, not only in identifying effective strategies for reaching them but also in persuasive communication and education in response to the unique reality of this population [40,41]. Pilot research could be considered in China and does not need to be overarching. On the contrary, preliminary programmes and services could consider establishing transgender support groups, providing them with IEC service on commercial sex, substance use counselling and referral services, all with the goal of reducing HIV epidemic among transgender women. Future efforts should be made towards the continual study on developing methods that are acceptable and accessible for them.

\section{Additional file}

Additional file 1: Multilingual abstracts in the five official working languages of the United Nations. (PDF $265 \mathrm{~kb}$ )

\begin{abstract}
Abbreviations
AIDS: Acquired Immune Deficiency Syndrome; aOR: Adjusted $O R$; CBO: Community-based Organization; CDC: Center for Disease Control and Prevention; Cl: Confidence intervals; COR: Crude odds ratios (s); HIV: Human Immunodeficiency Virus; IQR: Interquartile range; MSM: Men who have sex with men; STI: Sexually transmitted infection
\end{abstract}

\section{Acknowledgments}

We would like to thank the Division of Global HIV and TB China Office, Center for Global Health, US Center for Disease Control and Prevention for critical review and language polishing of the manuscript, and Nancy Yang from University of North California Project-China for English editing. And we thank the Division of AIDS Control and Prevention, Shanghai Municipal Center of Disease Control and Prevention; Division of AIDS Control and Prevention, Tianjin Center of Disease Control and Prevention, Shenlan Public Health Consulting Service Center in Tianjin, which were closely involved in this work.

\section{Funding}

This study was funded by M.A.C. AIDS Fund (A-P-15-20660). The funder had no role in study design, data collection and analysis, decision to publish, or preparation of the manuscript.

\section{Availability of data and materials}

Please contact the corresponding author for data requests.

\section{Authors' contributions}

DS and DPZ conceived and designed the study. DS, MHY, JY, MHZ and ZN performed the field work. DS and DPZ wrote the first draft of the manuscript. HL, LL, MJH revised the manuscript. All authors approved the final version of the manuscript.

\section{Ethics approval and consent to participate}

The study received approval from the Institutional Review Board of the National Center for AIDS/STD Control \& Prevention, China CDC (Approval number: X160729420). Subjects were provided with written informed consent and were given a unique identification number in order to protect each participant's privacy.

\section{Consent for publication}

All authors approved the manuscript and consent to its publication.

\section{Competing interests}

None of the authors have any competing interests in the manuscript.

\section{Author details}

${ }^{1}$ National Center for AIDS/STD Control and Prevention, Chinese Center for Disease Control and Prevention, Beijing 102206, People's Republic of China. ${ }^{2}$ Division of AIDS Control and Prevention, Tianjin Centers for Disease Control and Prevention, Tianjin 300011, People's Republic of China. ${ }^{3}$ Shenlan Public Health Consultation Service Center in Tianjin, Tianjin 300171, People's Republic of China. ${ }^{4}$ Division of AIDS Control and Prevention, Shanghai Municipal Center for Disease Control and Prevention, Shanghai 200336, People's Republic of China.

Received: 6 June 2018 Accepted: 16 November 2018

Published online: 01 December 2018

\section{References}

1. Herbst JH, Jacobs ED, Finlayson TJ, McKleroy VS, Neumann MS, Crepaz N. Estimating HIV prevalence and risk behaviors of transgender persons in the United States: a systematic review. AIDS Behav. 2008;12:1-17.

2. Soto RJ, Ghee AE, Nunez CA, Mayorga R, Tapia KA, Astete SG, et al. Sentinel surveillance of sexually transmitted infections/HIV and risk behaviors in vulnerable populations in 5 central American countries. J Acquir Immune Defic Syndr. 2007;46:101-11.

3. National Health and Family Planning Commission, P. R. China. China AIDS Response Progress Report, 2015. http://www.unaids.org.cn/cn/index/ Document_view.asp?id=875. Accessed 1 May 2015.

4. NCAIDS, NCSTD, China CDC. Update on the AIDS/STD epidemic in China in December, 2016. Chin J AIDS STD. 2017;23:93-4 (in Chinese).

5. State Council AIDS Working Committee Office, UN theme group on HIV/ AIDS in China. China HIV/AIDS Prevention and Control Joint Evaluation Report, 2007. http://www.chinaaids.cn/ddpg//hpgbg1/zgazbyq/201312/ t20131220_91605.htm. Accessed 5 Mar 2008.

6. National Health and Family Planning Commission, P. R. China. State Council's Five Year Action Plan for HIV Prevention (2016-2020). http://www. moh.gov.cn/jkj/s3585/201704/6d1bd3abf0a74a77b7039b735d6875fc.shtml. Accessed 18 Apr 2017. 
7. Feldman J, Romine RS, Bockting WO. HIV risk behaviors in the U.S. transgender population: prevalence and predictors in a large internet sample. J Homosex. 2014;61:1558-88.

8. Chen WK, Fu JH. Research progress on prevalence and risk factors of HIV among male-to-female transgenders. Chin J Epidemiol. 2015;36:1311-4 (in Chinese).

9. Reback CJ, Fletcher JB. HIV prevalence, substance use, and sexual risk behaviors among transgender women recruited through outreach. AIDS Behav. 2014;18:1359-67.

10. Operario D, Nemoto T. HIV in transgender communities: syndemic dynamics and a need for multicomponent interventions. J Acquir Immune Defic Syndr. 2010;55(Suppl 2):91-3.

11. Guadamuz TE, Wimonsate W, Varangrat A, Phanuphak P, Jommaroeng $R$, McNicholl JM, et al. HIV prevalence, risk behavior, hormone use and surgical history among transgender persons in Thailand. AIDS Behav. 2011;15:650-8.

12. WHO, UNAIDS, UNFPA, UNDP. A Hidden Epidemic: HIV. Men Who Have Sex with Men and Transgender People in Eastern Europe and Central Asia Regional Consultation. http://101.96.10.64/www.euro.who.int/_data/assets/ pdf_file/0010/140410/e94967.pdf. Accessed 24 Nov 2010.

13. Silva-Santisteban A, Raymond HF, Salazar X, Villayzan J, Leon S, McFarland W, et al. Understanding the HIV/AIDS epidemic in transgender women of Lima, Peru: results from a sero-epidemiologic study using respondent driven sampling. AIDS Behav. 2012;16:872-81.

14. World Bank. The Global HIV Epidemics among Men Who Have Sex with Men. https://elibrary.worldbank.org/doi/abs/10.1596/9780821387269_CH02. Accessed 1 May 2011.

15. Dong $\mathrm{YH}$, Wang $\mathrm{M}$, Dong HY. Investigation on lifestyles and behaviors of 45 cross-dressed male sex workers in Kunming. Chinese Journal of Health Education. 2009;25:635-6 (in Chinese).

16. Wang LL, Wang J, Zhang ML, Cai L. Survey on behavior characteristics among 152 cross-dressers involved in commercial sex in Harbin city. Chinese Journal of AIDS\&STD. 2008;14:619-20 (in Chinese).

17. Bai Y. Survey on the sexual behaviors of 20 cross-dressed male sex workers in Liuzhou. Chinese Journal of Preventive Medicine. 2011;12:43-5 (in (hinese).

18. Tianjin CDC. Internal document on HIV surveillance in 2016. Tianjin: Tianjin Center for Disease Control and Prevention; 2016.

19. Shanghai CDC. Internal document on HIV surveillance in 2016. Shanghai: Shanghai Center for Disease Control and Prevention; 2016.

20. Zhou Y, Li D, Lu D, Ruan Y, Qi X, Gao G. Prevalence of HIV and syphilis infection among men who have sex with men in China: a meta-analysis. Biomed Res Int. 2014;620431. https://doi.org/10.1155/2014/620431.

21. Green N, Hoenigl M, Morris S, Little SJ. Risk behavior and sexually transmitted infections among transgender women and men undergoing community-based screening for acute and early HIV infection in San Diego. Medcine. 2015;94:e1830. https://doi.org/10.1097/MD.0000000000001830.

22. Clements-Nolle K, Marx R, Guzman R, Katz M. HIV prevalence, risk behaviors, health care use, and mental health status of transgender persons: implications for public health intervention. Am J Public Health. 2001;91:915-21.

23. Rapues J, Wilson EC, Packer T, Colfax GN, Raymond HF. Correlates of HIV infection among transfemales, San Francisco, 2010: results from a respondent-driven sampling study. Am J Public Health. 2013;103:1485-92.

24. Hwahng SJ, Nuttbrock L. Sex workers, fem queens, and cross-dressers: differential marginalizations and HIV vulnerabilities among three ethnocultural male-to-female transgender communities in new York City. Sex Res Social Policy. 2007;4:36-59.

25. Gooren LJ, Sungkaew T, Giltay EJ, Guadamuz TE. Cross-sex hormone use, functional health and mental well-being among transgender men (toms) and transgender women (Kathoeys) in Thailand. Cult Health Sex. 2015;17:92-103.

26. Nemoto T, Operario D, Keatley J, Han L, Soma T. HIV risk behaviors among male-to-female transgender persons of color in San Francisco. Am J Public Health. 2004;94:1193-9.

27. Ellingson L, Odo C. HIV risk behaviors among Mahuwahine (native Hawaiian transgender women). AIDS Educ Prev. 2008;20(6):558-69.

28. Barrington C, Wejnert C, Guardado ME, Nieto Al, Bailey GP. Social network characteristics and HIV vulnerability among transgender persons in San Salvador: identifying opportunities for HIV prevention strategies. AIDS Behav. 2012;16:214-24

29. Chen X, Li X, Zheng J, Zhao J, He J, Zhang G, et al. Club drugs and HIV/STD infection: an exploratory analysis among men who have sex with men in
Changsha. China PLOS One. 2015;10:e126320. https://doi.org/10.1371/ journal.pone.0126320.

30. Wang Y, Li LL, Fan J, Zhao XH, Yang XL, Liu J, et al. Analysis on relationship of drug use behavior and HIV infection and related behaviors among men who have sex with men. Chinese Journal of Behavioral Medicine and Brain Science. 2013;22:364-6.

31. Sevelius JM, Reznick OG, Hart SL, Schwarcz S. Informing interventions: the importance of contextual factors in the prediction of sexual risk behaviors among transgender women. AIDS Educ Prev. 2009;21:113-27.

32. Horvath KJ, lantaffi A, Swinburne-Romine R, Bockting W. A comparison of mental health, substance use, and sexual risk behaviors between rural and non-rural transgender persons. J Homosex. 2014;61:1117-30.

33. Ostrow DG, Plankey MW, Cox C, Li X, Shoptaw S, Jacobson LP, et al. Specific sex drug combinations contribute to the majority of recent HIV seroconversions among MSM in the MACS. J Acquir Immune Defic Syndr. 2009;51:349-55.

34. Nuttbrock L, Bockting W, Rosenblum A, Hwahng S, Mason M, Macri M, et al. Gender abuse, depressive symptoms, and HIV and other sexually transmitted infections among male-to-female transgender persons: a threeyear prospective study. Am J Public Health. 2013;103:300-7.

35. Wiessing LG, van Roosmalen MS, Koedijk P, Bieleman B, Houweling $H$. Silicones, hormones and HIV in transgender street prostitutes. AIDS. 1999;13:2315-6.

36. Bockting WO. Transgender identity and HIV: resilience in the face of stigma. Focus. 2008;23:1-4.

37. Yang XS, Wang L, Hao C, Gu Y, Song W, Wang J, et al. Sex partnership and self-efficacy influence depression in Chinese transgender women: a crosssectional study. PLoS One. 2015;10:e136975. https://doi.org/10.1371/journal. pone. 0136975

38. Han MJ, Feng $L G$, Jiang $Y$, Shen $S$, Ling $H$, Ding $X B$, et al. Surveillance on HIV-1 incidence among men who have sex with men in Chongqing, China, 2006-2008. Chinese Journal of Epidemiology. 2009;30:878-81 (in Chinese).

39. Wu ZY, Xu J, Liu EW, Mao YR, Xiao Y, Sun XH, et al. HIV and syphilis prevalence among men who have sex with men: a cross-sectional survey of 61 cities in China. Clin Infect Dis. 2013;57:298-309.

40. Ickovics JR. "Bundling" HIV prevention: integrating services to promote synergistic gain. Prev Med. 2008:46:222-5.

41. UNDP, IRGT, UNFPA, UNAIDS, WHO, USAID, PEPFAR, UCSF Center of excellence for transgender health, Johns Hopkins Bloomberg School of Public Health. Implementing comprehensive HIV and STI programmes with transgender people-Practical guidance for collaborative interventions http:// www.who.int/hiv/pub/toolkits/transgender-implementation-tool/en/. Accessed 6 Apr 2016.

Ready to submit your research? Choose BMC and benefit from:

- fast, convenient online submission

- thorough peer review by experienced researchers in your field

- rapid publication on acceptance

- support for research data, including large and complex data types

- gold Open Access which fosters wider collaboration and increased citations

- maximum visibility for your research: over $100 \mathrm{M}$ website views per year

At $\mathrm{BMC}$, research is always in progress.

Learn more biomedcentral.com/submissions 